\title{
P065. Cluster headache: when to worry?
}

\author{
Matteo Bellamio ${ }^{1 *}$, Giulia Toldo ${ }^{1}$, Federico Mainardi ${ }^{2}$, Giorgio Zanchin ${ }^{1}$, Ferdinando Maggioni ${ }^{1}$ \\ From Abstracts from the 1st Joint ANIRCEF-SISC Congress \\ Rome, Italy. 29-31 October 2015
}

\section{Introduction}

Cluster headache $(\mathrm{CH})$ is a rare and disabling primary trigeminal autonomic cephalalgia which interests especially the male population with smoking and alcohol ingestion habits.

$\mathrm{CH}$ typically occurs at the same time of the day, once to eight times per day, and in the same period of the year. $\mathrm{CH}$ is featured by severe unilateral peri-orbital and/ or temporal pain lasting from 15 to 180 minutes if untreated, associated with at least one autonomic symptom (conjunctival injection, lacrimation, nasal congestion, rhinorrhea, facial sweating, miosis, ptosis and eyelid edema) [1]. $\mathrm{CH}$ secondary forms can be a manifestation of neurological pathologies such as brain tumor, cerebral venous thrombosis [2], arterial aneurisma or multiple sclerosis [3].

\section{Case report}

A 29-year-old man with silent medical history came to our observation on June $10^{\text {th }}$. Last December he experienced his first episode of headache described as rightsided pulsating pain, in fronto-orbital and nasal regions, which lasted two hours and recurred twice a day around 2.00 am and $2.00 \mathrm{pm}$; they were accompanied by ipsilateral conjuntival injection, lacrimation and rhinorrea. This episode ended just a few days later. At the end of April he reported a second episode with the same features but, after a week, the pain became more intense, pressing and localized all over the head associated with transient fluctuating reduction of visual acuity. He performed brain MRI which showed nonspecific white matter lesions localized in periventricular areas. He went to the Emergency Department presenting fever, signs of meningeal irritation and endocranial hypertension. During the hospitalization an MRI with vascular assessment was performed;

\footnotetext{
* Correspondence: matteo.bellamio@gmail.com

'Headache Centre, Department of Neurosciences, University of Padua, Padua, Italy

Full list of author information is available at the end of the article
}

it confirmed the white matter lesions and found a thrombosis in the left external jugular vein which climbed up to the distal portion of sigmoid sinus. Cerebrospinal fluid (CSF) isoelectric focusing after lumbar puncture was positive for oligoclonal bands in the gamma regions, while cytological, biochemical, serological, and virological findings of the CSF and blood were normal.

\section{Discussion}

According to 2013 ICHD-III criteria, our patient suffered from episodic $\mathrm{CH}$. In the literature we found data on cluster-like headache which can be the only manifestation of a secondary and more dangerous pathology. In our case both $\mathrm{CH}$ periods were not involved in the pathogenesis of thrombosis or CSF alterations. It is important to pay attention if there are any changes in headache in the patient's history because they could be a warning of a secondary form.

Written informed consent to publication was obtained from the patient(s).

\section{Authors' details}

${ }^{1}$ Headache Centre, Department of Neurosciences, University of Padua, Padua, Italy. ${ }^{2}$ Headache Centre, Neurological Division, SS Giovanni e Paolo Hospital, venice, Italy.

\section{Published: 28 September 2015}

\section{References}

1. Headache Classification Committee of the International Headache Society: The international classification of headache disorders: 3th edition (beta version). Cephalalgia 2013, 33:629-808.

2. Park Kl, et al: Cluster-like headache secondary to cerebral venous thrombosis. J Clin Neurol 2006, 2(1):70-73.

3. Mijajlović MD, et al: Cluster headache as a first manifestation of multiple sclerosis: case report and literature review. Neuropsychiatr Dis Treat 2014, 10:2269-2274.

\section{doi:10.1186/1129-2377-16-S1-A101}

Cite this article as: Bellamio et al:: P065. Cluster headache: when to worry? The Journal of Headache and Pain 2015 16(Suppl 1):A101.
SpringerOpen ${ }^{\odot}$

C 2015 Bellamio et al. This is an Open Access article distributed under the terms of the Creative Commons Attribution License (http:// creativecommons.org/licenses/by/4.0), which permits unrestricted use, distribution, and reproduction in any medium, provided the original work is properly cited. The Creative Commons Public Domain Dedication waiver (http://creativecommons.org/publicdomain/ zero/1.0/) applies to the data made available in this article, unless otherwise stated. 